\title{
ACÚMULO DE MASSA SECA NA SOJA EM RESPOSTA A APLICAÇÃO FOLIAR COM SILÍCIO SOB CONDIÇÕES DE DÉFICIT HÍDRICO
}

\author{
DRY MASS IN SOYBEAN IN RESPONSE TO APPLICATION LEAF WITH SILICON \\ UNDER CONDITIONS OF WATER DEFICIT
}

\begin{abstract}
Paulo Eduardo TEODORO' ${ }^{\text {; }}$ Larissa Pereira RIBEIRO² ; Elisa Pereira de OLIVEIRA ${ }^{3}$; Caio Cezar Guedes CORRÊA ${ }^{1}$; Francisco Eduardo TORRES ${ }^{4}$

1. Mestrandos em Produção da Universidade Estadual de Mato Grosso do Sul - UEMS, Unidade Universitária de Aquidauana UUA, MS, Brasil. eduteodoro@ hotmail.com; 2. Discente do curso de Agronomia da UEMS, UUA, MS, Brasil. 3. Doutoranda em Produção Vegetal da Universidade Estadual Paulista Júlio de Mesquita Filho, Faculdade de Ciências Agronômicas de Botucatu; 4. Professor, Doutor em Fitotecnia da UEMS, UUA, MS, Brasil.
\end{abstract}

\begin{abstract}
RESUMO: A adubação foliar com silício tem promovido diversas ações benéficas às plantas, dentre elas está a maior tolerância à deficiência hídrica, contudo, para a cultura da soja, são escassas informações destes benefícios nesta condição. Assim, objetivou-se, neste estudo, avaliar o efeito da aplicação de silício, via foliar, no acúmulo de massa seca da soja em seus estádios reprodutivos, onde a cultura sofreu deficiência hídrica durante os mesmos. O experimento foi realizado no setor de Fitotecnia da Unidade Universitária de Aquidauana - Universidade Estadual de Mato Grosso do Sul. O delineamento estatístico utilizado foi o de blocos ao acaso em parcelas subdivididas, com quatro repetições. As parcelas foram representadas pela cultivar de soja 5DR615, as subparcelas consistiram na aplicação (com e sem) de silício, cuja fonte utilizada foi o KSi. Mensurou-se a altura e identificou-se o estádio de desenvolvimento de todas as plantas, separando-as em haste + ramos, folhas + pecíolos, cápsulas de vagens e sementes, para avaliação quanto ao acúmulo de matéria seca. Em condições de déficit hídrico, a aplicação foliar de silício na soja proporcionou um desenvolvimento normal das plantas, gerando maior acúmulo de massa seca de haste + ramos, folhas + pecíolos, cápsulas de vagens e sementes durante toda sua fase reprodutiva, sendo os maiores valores obtidos no estádio R6 (35 dias após R2).
\end{abstract}

PALA VRAS-CHAVE: Adubação foliar. Estresse hídrico. Glycine max. Massa seca aérea.

\section{INTRODUÇÃO}

A soja [Glycine $\max (\mathrm{L}$.$) Merril] é a cultura$ com maior área cultivada no Brasil e, atualmente, encontra-se em expansão principalmente nas regiões Centro-Oeste e Norte (MOREIRA et al., 2010; TORRES et al., 2014). De acordo com números divulgados pela Companhia Nacional de Abastecimento (CONAB, 2013) em fevereiro de 2013, a área plantada desta cultura na safra 2012/2013 é de 27,7 milhões de hectares no Brasil. Estima-se que o país em 2013 se tornará o maior produtor mundial de soja, ultrapassando os Estados Unidos, alcançando a produtividade média de 3,1 toneladas por hectares (USDA, 2013).

O principal fator responsável por tais projeções é a seca histórica que os americanos vivenciam atualmente, onde a perda na produção de soja pode superar $10 \%$ daquela que era esperada a maior produção da história americana, 87 milhões de toneladas (USDA, 2013).

A ocorrência de déficit hídrico em plantas cultivadas afeta o crescimento e o desenvolvimento das culturas em todo o mundo. Segundo Ortolani e Camargo (1987), esta limitação é responsável por 60 a $70 \%$ da variabilidade final da produção, pois a água é essencial para vários processos morfofisiológicos nas plantas, como crescimento das células e manutenção da turgescência (SANTOS; CARLESSO, 1998). Diante disto, inúmeras pesquisas buscam uma possível solução para o problema mencionado, através do estudo das respostas das plantas ao déficit hídrico.

O silício ( $\mathrm{Si}$ ) não está no grupo dos elementos essenciais para o crescimento das plantas, mas a questão da sua essencialidade tem sido muito discutida por nutricionistas vegetais sem, contudo, que estes chegassem a um aspecto conclusivo (KORNDÖRFER et al., 1995). Acredita-se que este elemento pode aumentar a tolerância das plantas ao déficit hídrico, pois a acumulação de silício nos estômatos provoca a formação de uma dupla camada de sílica cuticular, a qual, pela redução da transpiração (DEREN, 2001), faz com que a exigência de água pelas plantas seja menor. O efeito da proteção mecânica é atribuído, principalmente, ao depósito de silício na forma de sílica amorfa $\left(\mathrm{SiO}_{2} \mathrm{nH}_{2} \mathrm{O}\right)$ na parede celular.

$\mathrm{Na}$ soja, esta barreira mecânica pode proporcionar redução no ataque de lagartas desfolhadoras (ZELIN et al., 2011) e percevejos (BUSSOLARO et al., 2011), além de reduzir a severidade da ferrugem asiática (PEREIRA et al., 
2009; CRUZ et al., 2013), principal doença desta cultura.

Desta forma, adubos contendo $\mathrm{Si}$ são atualmente usados em vários países, pois seu fornecimento para as culturas pode reduzir o uso de agroquímicos, proporcionando a obtenção de produto de maior qualidade, além de gerar menor impacto ambiental nos sistemas de produção. Assim, este elemento tem sido considerado chave para a sustentabilidade, não apenas da agricultura convencional, mas também da agricultura orgânica e biodinâmica (KORNDÖRFER, 2006).

As pesquisas sobre o efeito do silício nos componentes produtivos e produtividade da soja demonstram resultados heterogêneos. Enquanto alguns demonstram incremento nestes parâmetros (MOREIRA et al., 2010; BUSSOLARO et al., 2011; ZELIN et al., 2011; CRUSCIOL et al., 2013), Juliatti et al. (2004) e Pereira Júnior et al. (2010) não verificaram quaisquer benefícios da adubação silicatada. Deste modo, são necessárias pesquisas que comprovem o efeito desta prática na fisiologia e crescimento da cultura da soja sob condições adversas, como déficit hídrico.

A análise de crescimento, por meio da quantificação da massa seca é uma importante ferramenta para entender o comportamento das diversas cultivares que existem atualmente, considerando que vários processos fisiológicos que afetam o desenvolvimento da planta estão relacionados com este parâmetro (BRANDELERO et al., 2002; BENICASA, 2003).

Neste contexto, o objetivo do trabalho foi avaliar o efeito da adubação silicatada no acúmulo de massa seca durante os estádios reprodutivos da cultura da soja, sob condições de déficit hídrico.

\section{MATERIAL E MÉTODOS}

O experimento foi instalado na área experimental da Universidade Estadual de Mato Grosso do Sul - Unidade Universitária de Aquidauana (UEMS/UUA), setor Fitotecnia, localizado no bioma Cerrado, situado no município de Aquidauana, MS, compreendendo as seguintes coordenadas geográficas $20^{\circ} 27^{\prime} \mathrm{S}$ e $55^{\circ} 40^{\prime} \mathrm{W}$ com uma altitude média de $170 \mathrm{~m}$.

O solo da área foi classificado como Argissolo Vermelho-Amarelo distrófico de textura arenosa (EMBRAPA, 2006), com as seguintes características na camada de $0-0,20 \mathrm{~m}: \mathrm{pH}\left(\mathrm{H}_{2} \mathrm{O}\right)=$ 6,2; $\mathrm{Al}$ trocável $\left(\mathrm{cmol}_{\mathrm{c}} \mathrm{dm}^{-3}\right)=0,0 ; \mathrm{Ca}+\mathrm{Mg}\left(\mathrm{cmol}_{\mathrm{c}}\right.$ $\left.\mathrm{dm}^{-3}\right)=4,31 ; \mathrm{P}\left(\mathrm{mg} \mathrm{dm}^{-3}\right)=41,3 ; \mathrm{K}\left(\mathrm{cmol}_{\mathrm{c}} \mathrm{dm}^{-3}\right)=$ 0,2 ; Matéria orgânica $\left(\mathrm{g} \mathrm{dm}^{-3}\right)=19,74 ; \mathrm{V}(\%)=45$; $\mathrm{m}(\%)=0,0$; Soma de bases $\left(\mathrm{cmol}_{\mathrm{c}} \mathrm{dm}^{-3}\right)=2,3$;
CTC $\left(\mathrm{cmol}_{\mathrm{c}} \mathrm{dm}^{-3}\right)=5,1$. O clima da região, segundo a classificação descrita por Köppen-Geiger é do tipo Aw (Tropical de Savana) com precipitação média anual de $1200 \mathrm{~mm}$ e temperaturas máximas e mínimas de 33 e $19^{\circ} \mathrm{C}$, respectivamente (SCHIAVO et al., 2010).

O delineamento experimental utilizado foi o de blocos inteiramente casualizados em esquema de parcelas subdivididas, com quatro repetições. As parcelas foram representadas pela cultivar de soja 5DR615 (ciclo superprecoce, hábito de crescimento indeterminado e grau de maturação 6.1). As subparcelas consistiram na aplicação (com e sem) de silício, cuja fonte utilizada foi o $\mathrm{KSi}$ ( $\%$ de $\mathrm{K}_{2} \mathrm{O}$ e \% de Si).

$\mathrm{Na}$ preparação da área experimental, foi realizada uma dessecação com o herbicida Roundup $\mathrm{WG}^{\circledR}$, com ingrediente ativo glyphosate, na dose de $2 \mathrm{~kg} \mathrm{ha}^{-1}$. Após a secagem e a morte completa das plantas, os sulcos foram abertos com utilização de uma semeadora simples, realizando semeadura manualmente sob sistema de plantio direto no dia 02/11/2012, dez dias após a dessecação.

As sementes foram tratadas com fungicida a base de benomyl (50 g $100 \mathrm{~kg}^{-1}$ de sementes) e inoculadas com Bradyrhizobium japonicum $(500 \mathrm{~g}$ de inoculante turfoso $50 \mathrm{~kg}$ de sementes ${ }^{-1}$ ), sendo distribuídas 13,5 sementes por metro na linha de plantio, no espaçamento de $0,45 \mathrm{~m}$, para estabelecimento de 300.000 plantas $\mathrm{ha}^{-1}$. A adubação no momento da semeadura constituiu de $300 \mathrm{~kg} \mathrm{ha}^{-1}$ da formulação 0-20-20. Para o controle das plantas invasoras realizou-se aplicação do herbicida Roundup $\mathrm{WG}^{\circledR}$, com ingrediente ativo glyphosate, na dose de $2 \mathrm{~kg} \mathrm{ha}^{-1}$ aos 20 dias após a emergência da cultura.

A primeira aplicação de silício foi realizada no estádio V3, a segunda em V8 e a terceira em R5, de acordo com a escala fenológica proposta por Fher et al. (1971). A dose utilizada em todas as aplicações foi de $500 \mathrm{~mL} \mathrm{ha}^{-1}$ com volume de calda de $400 \mathrm{~L} \mathrm{ha}^{-1}$, utilizando-se pulverizador costal dirigido.

Para a determinação da produção de matéria seca foram realizadas amostragens semanais a partir do início do florescimento (R2) até o estádio R8, coletando-se aleatoriamente cinco plantas em cada subparcela experimental. Cada amostra foi etiquetada no campo e, a seguir, transportada para o laboratório, onde se realizou a contagem do número de plantas, mediu-se a altura e identificou-se o estádio de desenvolvimento de todas as plantas, baseando-se em Fehr et al. (1971).

Posteriormente, destacou-se se as folhas + pecíolos e vagens quando presentes. As vagens 
foram separadas de acordo com seu estádio de desenvolvimento (FEHR et al., 1971) e a seguir contadas e colocadas para secar. Quando as vagens continham sementes, após a secagem, estas também foram separadas. Portanto, haste + ramos, folhas + pecíolos, cápsulas de vagens e sementes, foram as partes das plantas avaliadas quanto ao acúmulo de matéria seca. Todas as partes foram colocadas para secar em estufa com circulação forçada de ar a $65^{\circ} \mathrm{C}$, até atingirem peso constante, sendo a seguir pesadas em balança de precisão com duas casas decimais e determinada à produção de matéria seca/ha. A matéria seca total da parte aérea foi obtida com a soma da matéria seca de suas partes constituintes (hastes + ramos, folhas + pecíolos, cápsulas de vagens e sementes).

$\mathrm{Na}$ Tabela 1 são apresentados os valores médios mensais de temperatura, umidade relativa do ar e precipitação durante o período de condução deste experimento, onde é possível verificar que a precipitação acumulada não atendeu a necessidade hídrica para a cultura da soja, que varia entre 450 e $800 \mathrm{~mm}$ por ciclo (EMBRAPA, 2008), caracterizando, portanto, um déficit hídrico para a mesma.

Tabela 1. Estádio de desenvolvimento, disponibilidade de água no solo, temperatura e umidade média e precipitação acumulada entre os meses de condução do experimento em Aquidauana, MS, Brasil.

\begin{tabular}{cccccc}
\hline $\begin{array}{c}\text { Estádio de } \\
\text { desenvolvimento }\end{array}$ & Mês/Ano & $\begin{array}{c}\text { Temperatura } \\
\text { média }\end{array}$ & $\begin{array}{c}\text { Disponibilidade } \\
\text { de água no solo }\end{array}$ & $\begin{array}{c}\text { Umidade } \\
\text { média }\end{array}$ & $\begin{array}{c}\text { Precipitação } \\
\text { acumulada }\end{array}$ \\
\hline--- & --- & $---{ }^{\circ} \mathrm{C}---$ & $---\mathrm{mm}---$ & $--\%$-- & --- mm --- \\
\hline Vegetativo & Novembro/2012 & 28,60 & 38,50 & 61,50 & 76,60 \\
Vegetativo & Dezembro/2012 & 29,20 & 37,20 & 60,75 & 86,40 \\
Reprodutivo & Janeiro/2013 & 27,90 & 25,40 & 56,75 & 58,30 \\
Reprodutivo & Fevereiro/2013 & 28,65 & 9,70 & 63,75 & 31,80 \\
\hline
\end{tabular}

Com auxílio do software estatístico Assistat (SILVA; AZEVEDO, 2002), foi feita análise das épocas de amostragem de matéria seca, sendo as médias dos resultados de cada variável submetidas à análise de variância (teste F) e, posteriormente, a estudos de regressão polinomial.

\section{RESULTADOS E DISCUSSÃO}

Na Figura 1 estão apresentados os valores médios para a variável altura da planta, onde ambos os tratamentos apresentaram comportamento quadrático. A aplicação foliar de silício proporcionou maior altura de plantas $(\mathrm{P}<0,01)$ durante todos os estádios reprodutivos da cultura da soja em relação à testemunha $(\mathrm{P}<0,01)$, onde os valores máximos encontrados foram de 105,9 e 94,0 $\mathrm{cm}$, respectivamente, ambos encontrados em R5 (28 dias após R2).

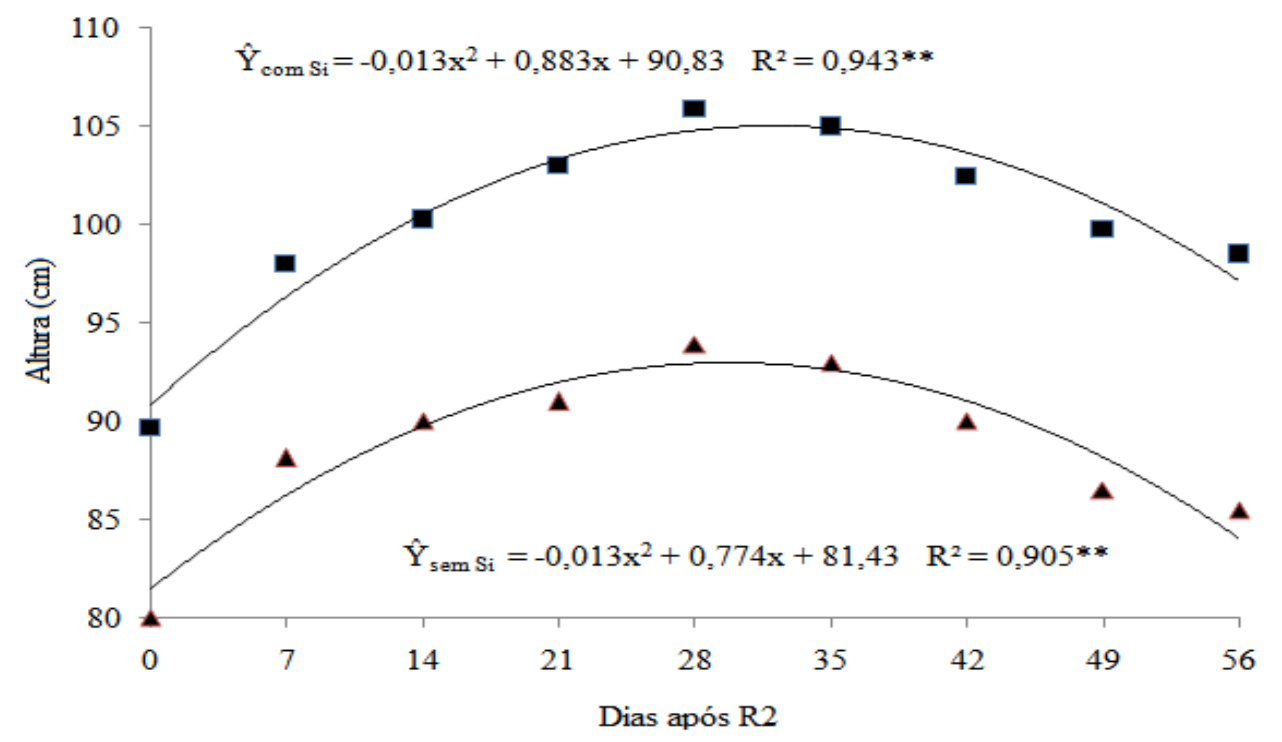

Figura 1. Valores médios de altura da cultivar de soja 5DR615 cultivada com e sem aplicação foliar com silício em Aquidauana, MS, 2013. 
Normalmente a aplicação de Si estimula várias ações na planta, tais como: maior rigidez estrutural dos tecidos, por aumento da resistência mecânica das células, redução da transpiração, folhas mais eretas e diminuição do autosombreamento (DEREN, 2001), podendo esperar maior crescimento efetivo da planta, o que foi evidenciado nesse experimento. Estes resultados se assemelham aos verificados por Pereira Júnior et al. (2010), onde a aplicação de $350 \mathrm{~kg} \mathrm{ha}^{-1}$ de silício aplicado no sulco de plantio propiciou maior altura às plantas de soja.
Comparando os dados desta variável com Lazarini (2000), a aplicação foliar de silício proporcionou desenvolvimento normal da cultura, minimizando a influência das condições climáticas.

Os valores de massa seca de hastes + ramos são demonstrados na Figura 2, onde ambos apresentaram comportamento quadrático $(\mathrm{P}<0,01)$. O decréscimo deste parâmetro a partir de R6 (35 dias após R2) é explicado pela translocação de carboidratos solúveis ali acumulados para o desenvolvimento das sementes (COSTA; COSTA, 1982; HANWAY; WEBER, 1971).

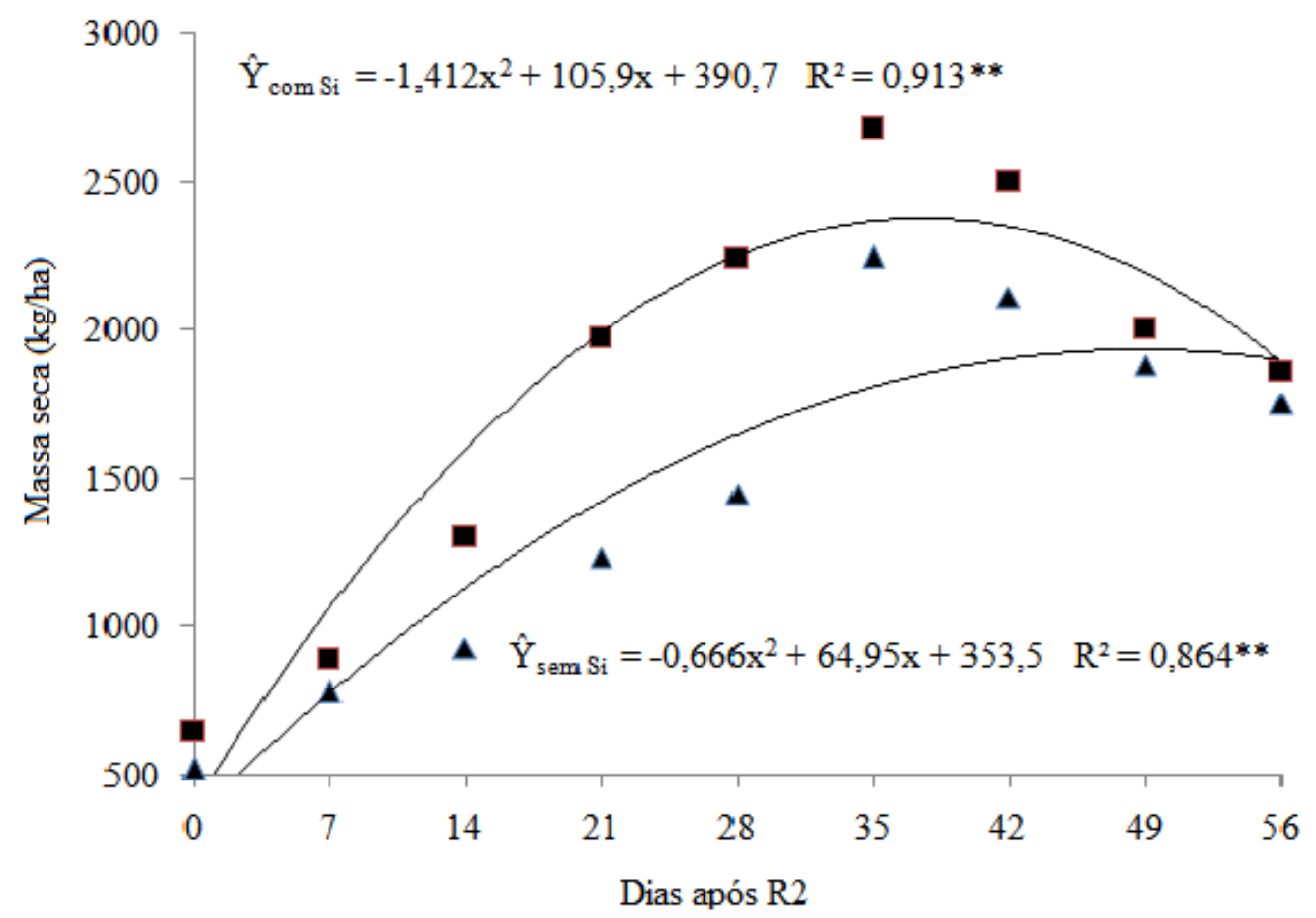

Figura 2. Valores médios de massa seca de hastes + ramos da cultivar de soja 5DR615 cultivada com e sem aplicação foliar com silício em Aquidauana, MS, 2013.

Pode se observar que o tratamento que recebeu aplicação foliar com silício obteve valores médios sempre superiores à testemunha, onde em R6 ambos alcançaram a maior produção com respectivamente, $2.679,9$ e $2.245,4 \mathrm{~kg} \mathrm{ha}^{-1}$. As aplicações de Si proporcionaram a cultivar avaliada maior produção de massa seca de hastes + ramos durante toda a fase reprodutiva da cultura, provavelmente pelo aumento da capacidade fotossintética das plantas e melhor eficiência no uso da água (KORNDÖRFER et al., 1995).

Na Figura 3 estão apresentados os valores médios para a variável massa seca das folhas + pecíolos, onde ambos os tratamentos apresentaram comportamento quadrático. Para este parâmetro, a aplicação foliar de silício proporcionou valores superiores $(\mathrm{P}<0,01)$ durante todos os estádios reprodutivos da cultura da soja em relação à testemunha $(\mathrm{P}<0,05)$, onde os valores máximos encontrados foram de $1.696,0$ e $1.238,3 \mathrm{~kg} \mathrm{ha}^{-1}$, respectivamente, ambos encontrados em R6 (35 dias após R2).

Estes dados corroboram os observados por Moreira et al. (2010), que ao avaliar a aplicação foliar de silício na cultura da soja, constatou que as plantas que receberam este tratamento apresentaram os maiores valores de massa seca das folhas durante o seu ciclo.

De acordo com Agarie et al. (1998), o silício pode estar associado à retenção foliar e acúmulo de fitomassa nas folhas, devido à manutenção da fotossíntese e distribuição de clorofila em condições de altas temperaturas e baixa umidade do ar. Esse elemento também pode estar envolvido na estabilidade térmica dos lipídios das membranas celulares em condições de estresse 
hídrico. Essa constatação pode explicar os resultados obtidos neste experimento, pois ambas as condições climáticas ocorreram durante a condução do mesmo.

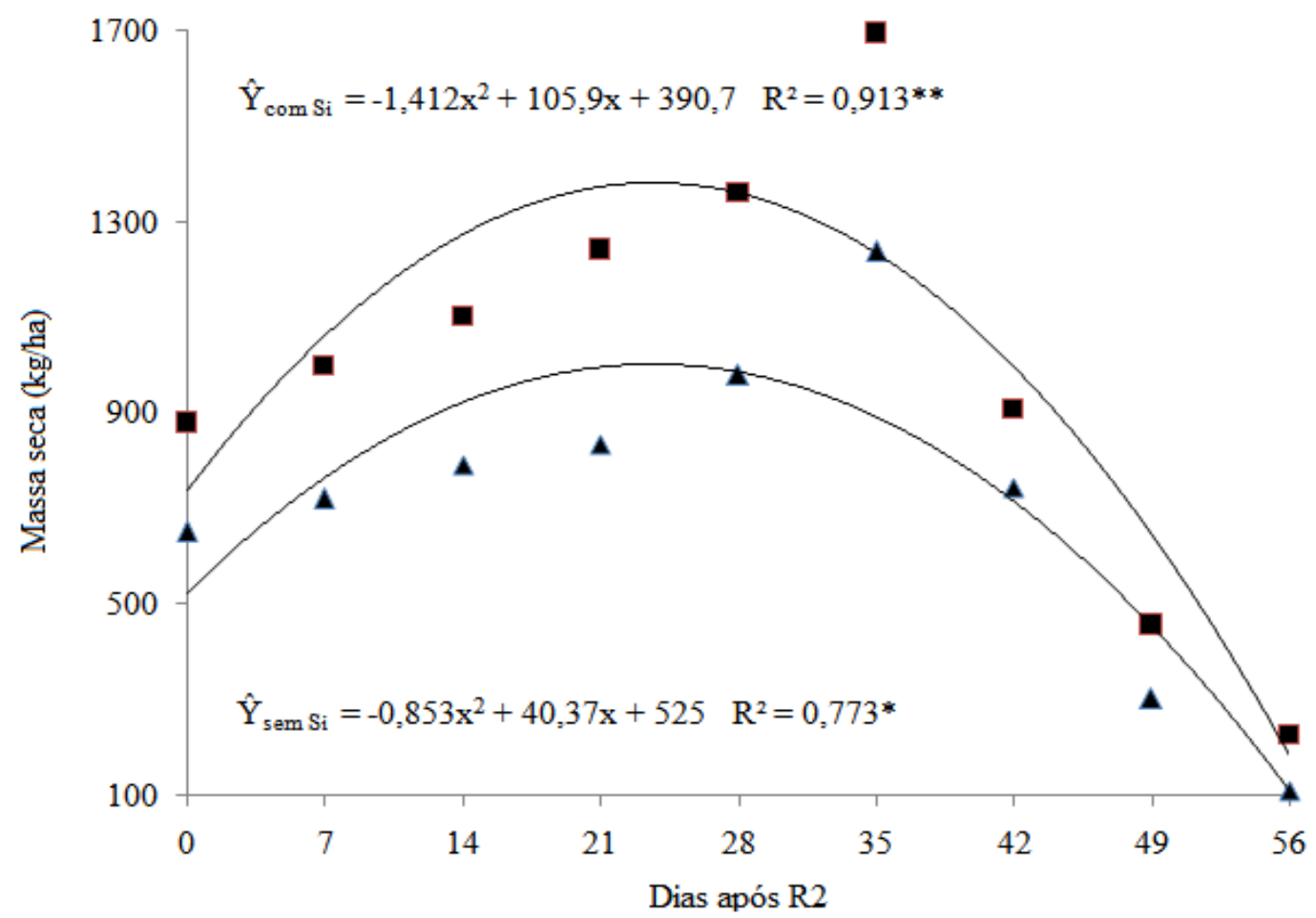

Figura 3. Valores médios de massa seca das folhas + pecíolos da cultivar de soja 5DR615 cultivada com e sem aplicação foliar com silício em Aquidauana, MS, 2013.

Na Figura 4 estão apresentados os valores médios para o parâmetro massa seca das cápsulas de vagens, onde ambos os tratamentos apresentaram comportamento quadrático.

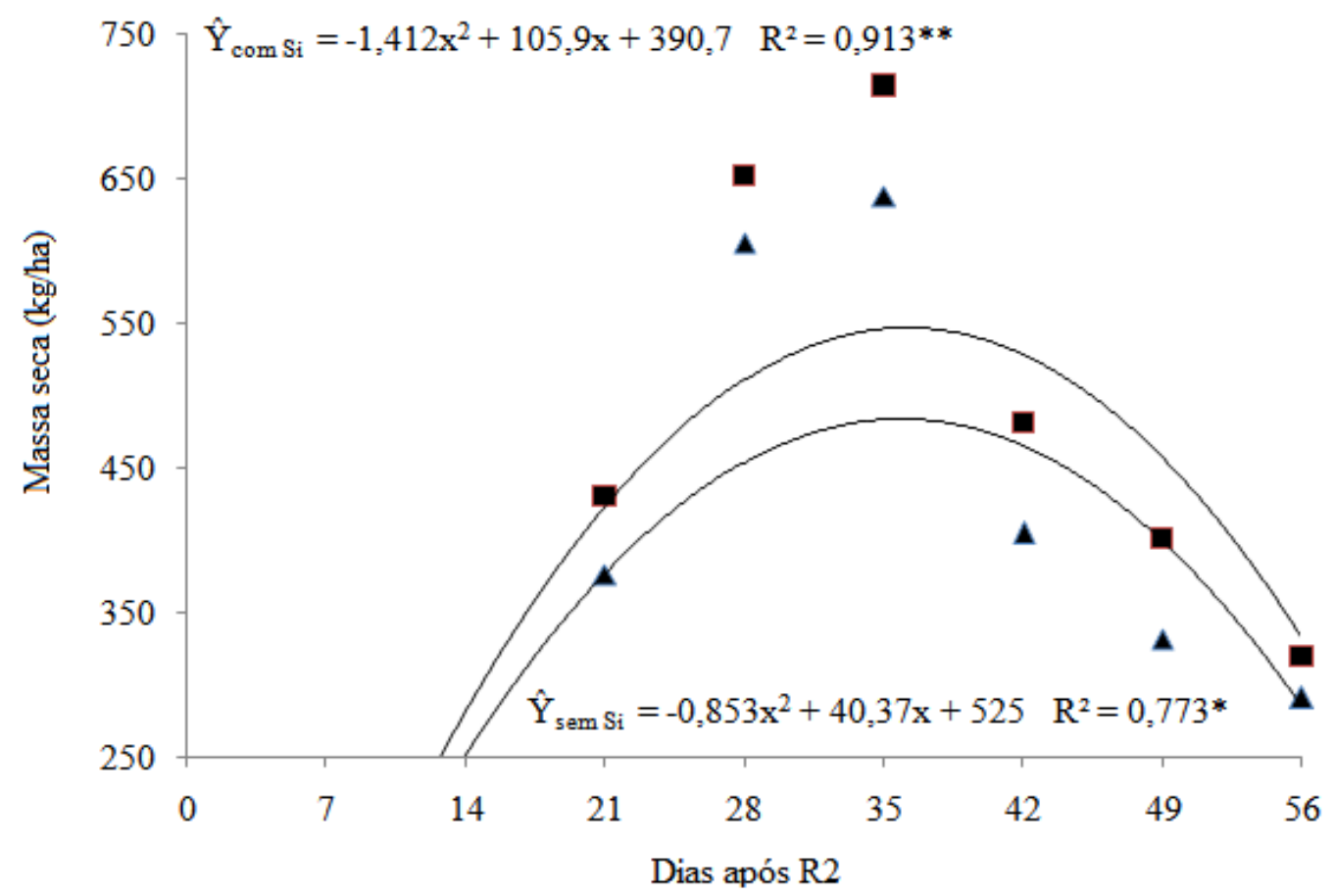

Figura 4. Valores médios de massa seca das cápsulas de vagens da cultivar de soja 5DR615 cultivada com e sem aplicação foliar com silício em Aquidauana, MS, 2013. 
Para esta variável, aplicação foliar de silício proporcionou valores superiores $(\mathrm{P}<0,01)$ durante todos os estádios reprodutivos da cultura da soja em relação à testemunha $(\mathrm{P}<0,05)$, onde os valores máximos encontrados foram de 714,5 e $638,2 \mathrm{~kg}$ ha ${ }^{1}$, respectivamente, ambos encontrados em R6 (35 dias após R2). Lazarini et al. (2000), ao avaliarem o acúmulo de matéria seca nos estádios reprodutivos da soja, também observaram comportamento quadrático da produção deste parâmetro, onde foi crescente até o início do estádio R6, devido principalmente ao seu desenvolvimento em tamanho, onde partir de então, decresceu gradualmente.

Os valores de massa seca das sementes são demonstrados na Figura 5, onde ambos apresentaram comportamento linear $(\mathrm{P}<0,01)$.

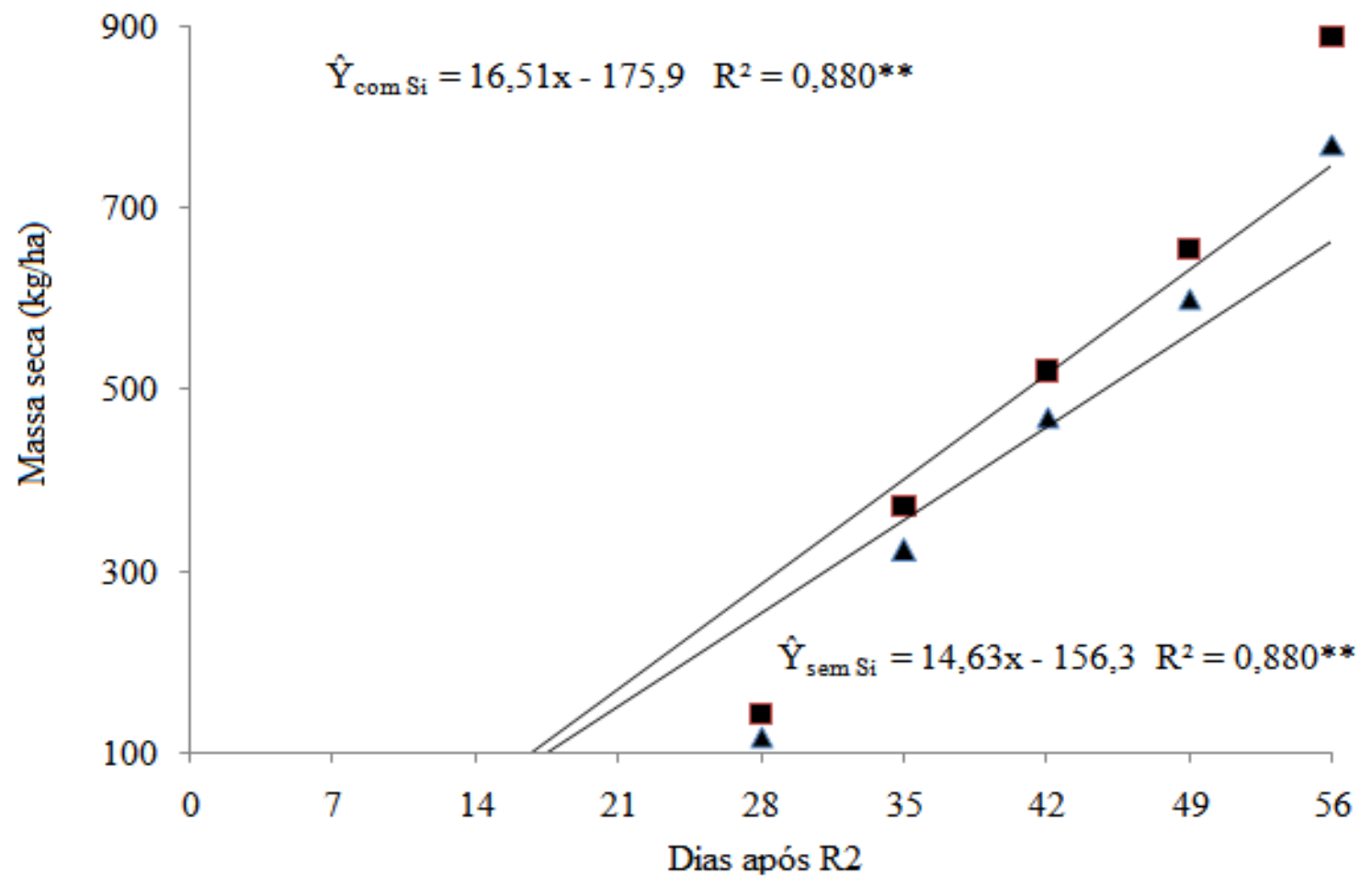

Figura 5. Valores médios de massa seca das sementes da cultivar de soja 5DR615 cultivada com e sem aplicação foliar com silício em Aquidauana, MS, 2013.

Pode se observar que o tratamento que recebeu aplicação foliar com silício obteve valores médios superiores em relação à testemunha, onde em R9 ambos alcançaram a maior produção com respectivamente, 890,0 e $770,0 \mathrm{~kg} \mathrm{ha}^{-1}$. Estes valores estão de acordo com Moreira et al. (2010) e Crusciol et al. (2013), que encontraram incremento na produtividade da soja adubada com silício via foliar, porém discordam de Pereira Júnior et al. (2010) que, ao estudar a adubação silicatada aplicada no solo, não constataram aumento para o mesmo parâmetro.

Os efeitos benéficos do $\mathrm{Si}$ têm sido demonstrados em várias espécies vegetais, especialmente quando essas plantas são submetidas a algum tipo de estresse, seja ele de caráter biótico ou abiótico (MA et al., 2001; TEODORO et al.,
2014). Com relação à deficiência hídrica, o efeito benéfico do Si foi comprovado por Pulz et al. (2008), que ao avaliarem a produção de batata sob estresse hídrico, verificaram maior tolerância dos tratamentos que receberam adubação silicatada em relação à testemunha.

Na Figura 6 estão apresentados os valores médios para a variável massa seca total da parte aérea, onde ambos os tratamentos apresentaram comportamento quadrático. Para este parâmetro, aplicação foliar de silício proporcionou valores superiores $(\mathrm{P}<0,01)$ durante todos os estádios reprodutivos da cultura da soja em relação à testemunha $(\mathrm{P}<0,01)$, onde os valores máximos encontrados foram de $5.021,3$ e $4.445,3 \mathrm{~kg} \mathrm{ha}^{-1}$, respectivamente, ambos encontrados em R6 (35 dias após R2). 


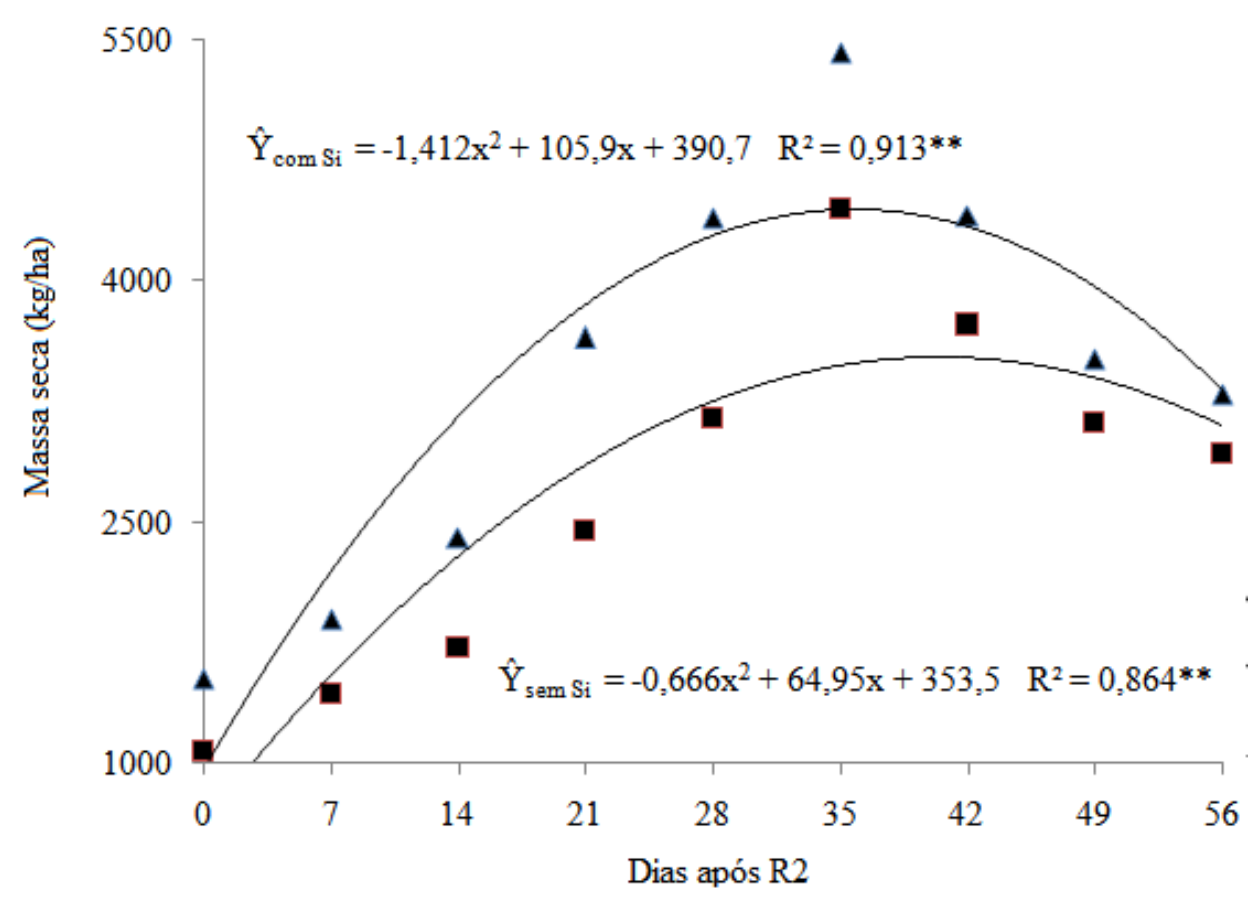

Figura 6. Valores médios de massa seca total da parte aérea da cultivar de soja 5DR615 cultivada com e sem aplicação foliar com silício em Aquidauana, MS, 2013.

Pereira Júnior et al. (2010), ao avaliar a resposta da cultura da soja a aplicação foliar de silício, observaram maior produção de massa seca total da parte aérea com a adubação silicatada, concordando com o presente experimento. De acordo com Deren (2001), o acúmulo de sílica ou silício na folha provoca redução na transpiração e faz com que a exigência de água pelas plantas seja menor, devido à formação de uma dupla camada de sílica, o que causa redução da transpiração por diminuir a abertura dos estômatos limitando a perda de água, em condições de déficit hídrico.

O aumento no acúmulo de massa seca total na fase reprodutiva é um fator determinante na produtividade das culturas. Board e Modali (2005) ressaltam que este acúmulo a partir do estádio R2 e durante o R7 é um componente importante para estimar a produtividade da cultura de soja. Isto ocorre devido a maior interceptação de radiação solar e partição de fotoassimilados para os órgãos reprodutivos, o que auxilia na maximização da produtividade. Portanto, os dados observados nesta pesquisa elucidam a importância do efeito ocasionado pela aplicação de silício foliar no acúmulo de massa seca total na fase reprodutiva, sob condições de déficit hídrico.

\section{CONCLUSÃO}

Em condições de déficit hídrico, a aplicação foliar de silício na soja proporcionou um desenvolvimento normal das plantas, gerando maior acúmulo de massa seca de haste + ramos, folhas + pecíolos, cápsulas de vagens e sementes durante toda sua fase reprodutiva, sendo os maiores valores obtidos no estádio R6 (35 dias após R2).

\footnotetext{
ABSTRACT: The foliar fertilization with silicon has promoted several actions beneficial to plants, among them is greater drought tolerance, however, for the soybean, there is little information on these benefits in this condition. Thus, the aim of this study was to evaluate the effect of silicon on leaf, the dry matter accumulation of soybean in their reproductive stages, where the crop water stress suffered during the same. The experiment was carried out at the Plant Science Unit Aquidauana University - State University of Mato Grosso do Sul. The statistical design was a randomized block split plot with four replications. The plots were represented by cultivar 5DR615, the subplots consisted of the application (with or without) silicon, whose source was used KSi. Was measured the height and identified the development stage of all plants, separating them into stem + branches, leaves + petioles, pods capsules and seed. Foliar applications of silicon increased dry matter accumulation during the reproductive stage of soybean, where the highest values occurred in the R6 stage. Under conditions of water deficit, foliar application of silicon on soybean provided normal plant development, generating greater dry mass of stem + branches, leaves + petioles, pods capsules and seeds throughout their reproductive phase, with the highest values obtained at R6 stage (35 days after R2).
} 
KEYWORDS: Foliar fertilization. Water stress. Glycine max. Dry mass air.

\section{REFERÊNCIAS}

AGARIE, S.; AGATA, W.; KAUFMAN, P. B. Involvement of silicon in the senescence of rice leaves. Plant Production Science, Tokyo, v. 1, n. 2, p. 104-105, 1998. http://dx.doi.org/10.1626/pps.1.104

BRANDELERO E.; PEIXOTO, C. P.; M SANTOS, J. M. B.; MORAES, J. C. C; PEIXOTO, M. F. S. P.; SILVA V. Índices fisiológicos e rendimento de cultivares de soja no Recôncavo Baiano. Magistra, Cruz das Almas, v. 14, p.77-88, 2002.

BENICASA, M. M. P. Análise do crescimento de plantas (noções básicas). 2. ed. Jaboticabal: FUNEP, 2003. $41 \mathrm{p}$.

BOARD, J. E.; MODALI, H. Dry matter accumulation predictors for optimal yield in soybean. Crop Science, Madison, v. 45, p. 1790-1799, 2005. http://dx.doi.org/10.2135/cropsci2004.0602

BUSSOLARO, I.; ZELIN, E.; SIMONETTI, A. P. M. M. Aplicação de silício no controle de percevejos e produtividade da soja. Cultivando o saber, Cascavel, v. 4, n. 3, p. 9-19, 2011.

CONAB: Companhia Nacional de Abastecimento. Indicadores da Agropecuária, Brasília, n. 3, março, 2013.

COSTA, J. A.; COSTA, O. M. M. Avaliação de caracteres fisiológicos associados ao rendimento da soja. In: SEMINÁRIO NACIONAL DE PESQUISA DE SOJA, 2, 1981, Brasília. Anais... Londrina:

EMBRAPA/CNPSo, 1982. v.1, p.50-64.

CRUSCIOL, C. A. C.; SORATTO, R. P.; CASTRO, G. S. A.; COSTA, C. H. M.; FERRARI NETO, J. Aplicação foliar de ácido silícico estabilizado na soja, feijão e amendoim. Revista Ciência Agronômica, Fortaleza, v. 44, n. 2, p. 404-410, 2013. http://dx.doi.org/10.1590/S1806-66902013000200025

CRUZ, M. F.; RODRIGUES, F. A.; DINIZ, A. P. C.; MOREIRA, M. A.; BARROS, E. G. Potassium silicate and calcium silicate on the resistance of soybean to Phakopsora pachyrhizi infection. Bragantia, Campinas, v. 72, n. 4, p. 373-377, 2013. http://dx.doi.org/10.1590/brag.2013.052

DEREN, C. Plant genotypes, silicon concentration and silicon related responses. In: DATNOFF, L. E.; SNYDER, G. H.; KORNDÖRFER, G.H. Silicon in Agriculture. Netherlands: Elsevier Science, 2001. cap. 8, p. $149-158$.

EMBRAPA. Sistema brasileiro de classificação de solos. 2. ed. Rio de Janeiro: Embrapa/CNPS, 2006. 306 p.

EMBRAPA. Tecnologias de produção de soja - região central do Brasil - 2009 e 2010. 13 ed. Londrina: Embrapa Soja, 2008. 262 p.

FEHR, W. R.; CAVINESS, C. E.; BURMOOD, D. T.; PENNINGTON, J. S. Stage of development descriptions for soybeans (Glycine max (L.) Merrill). Crop Science, Madison, v. 11, n.6, p.929-931, 1971. http://dx.doi.org/10.2135/cropsci1971.0011183X001100060051x

HANWAY, J. J.; WEBER, C. R. Dry matter accumulation in eight soybean (Glycine max (L.) Merrill) varieties. Agronomy Journal, Madison, v. 63, n. 2, p. 227-230, 1971.

http://dx.doi.org/10.2134/agronj1971.00021962006300020009x 
JULIATTI, F. C.; PEDROSA, M. G.; LANA, R. M. Q.; BRITO, S. H.; MELO, B. Influência do silício na redução de podridão de sementes por Fusarium semitectum na cultura da soja. Bioscience Journal, Uberlândia, v. 20, n. 2, p. 57-63, 2004.

KORNDORFER, G. H. Eficiência do silício como corretivo de solo. Revista Campo e Negócios, Uberlândia, v. 4, n. 42, p. 84-85, 2006.

KORNDÖRFER, G. H.; DATNOFF, L. E. Adubação com silício: uma alternativa no controle de doenças da cana-de-açúcar e do arroz. Informações Agronômicas, Piracicaba, v. 70, p. 1-5, 1995.

LAZARINI, E.; SÁ, M. E.; FERREIRA, R. C. Acúmulo de matéria seca em plantas de soja durante os estádios reprodutivos e qualidade fisiológica de sementes colhidas em diferentes fases do desenvolvimento. Revista

Brasileira de Sementes, Londrina. v. 22, n. 1, p. 153-162, 2000.

MA, J. F.; MIYAKE, Y.; TAKAHASHI, E. Silicon as a benefic element for crop plants. In: DATNOFF, L. E.; SNYDER, G. H.; KORNDÖRFER, G.H. (Eds.) Silicon in agriculture. Amsterdam: Elsevier, 2001. p.17-39. http://dx.doi.org/10.1016/S0928-3420(01)80006-9

MOREIRA, A. R.; FAGAN, E. B.; MARTINS, K. V.; SOUZA, C. H. E. Resposta da cultura da soja a adubação de silício foliar. Bioscience Journal, Uberlândia, v. 26, n. 3, p. 413-423, 2010.

PEREIRA, S. C.; RODRIGUES, F. A.; CARRÉ-MISSIO, V.; OLIVEIRA, M. G. A.; ZAMBOLIM, L. Aplicação foliar de silício na resistência da soja à ferrugem e na atividade de enzimas de defesa. Tropical Plant Pathology, Viçosa, v. 34, n. 3, p. 164-170, 2009.

PEREIRA JÚNIOR, P.; REZENDE, P. M.; MALFITANO, S. C.; LIMA, R. K.; CORRÊA, L. V. T.; CARVALHO, E. R. Efeito de doses de silício sobre a produtividade e características agronômicas da soja [Glycine max (L.) Merrill]. Revista Ciência e Agrotecnologia, Lavras, v. 34, n. 4, p. 908-913, 2010.

PULZ, A. L.; CRUSCIOL, C. A. C.; LEMOS, L. B.; SORATTO, R. P. Influência de silicato e calcário na nutrição, produtividade e qualidade da batata sob deficiência hídrica. Revista Brasileira de Ciência Solo, Viçosa, v. 32, p. 1651-1659, 2008.

ORTOLANI, A. A.; CAMARGO, M. B. P. Influência dos fatores climáticos na produção. In: CASTRO, P.R.C.; FERREIRA, S.O.; YAMADA, T. Ecofisiologia da produção agrícola. Piracicaba: Instituto da Potassa e Fosfato, 1987. p. 71-100.

SCHIAVO, J. A.; PEREIRA, M. G.; MIRANDA, L. P. M.; DIAS NETO, A. H.; FONTANA, A. Caracterização e classificação de solos desenvolvidos de arenitos da formação Aquidauana-MS. Revista Brasileira de Ciência do Solo, Viçosa, v. 34, n. 3, p. 881-889, 2010.

SANTOS, R. F.; CARLESSO, R. Déficit hídrico e os processos morfológico e fisiológico das plantas. Revista Brasileira de Engenharia Agrícola e Ambiental, Campina Grande, v. 2, n. 3, p.287-294, 1998.

SILVA, F. A. S.; AZEVEDO, C. A. V. Versão do programa computacional Assistat para o sistema operacional Windows. Revista Brasileira de Produtos Agroindustriais, Campina Grande, v. 4, n. 1, p. 71-78, 2002.

TEODORO, P. E.; RIBEIRO, L. P.; CORRÊA, C. C. G.; TORRES, F. E. Desempenho de híbridos de milho sob aplicação foliar de silício no Cerrado Sul-Mato-Grossense. Bioscience Journal, Uberlandia, v. 30, supplement 1, p. 224-231, 2014a.

TORRES, F. E.; SILVA, E. C.; TEODORO, P. E.; Desempenho de genótipos de soja nas condições edafoclimáticas do ecótono Cerrado-Pantanal. Interações, Campo Grande, v. 15, n. 1, p. 71-78, jan./jun. 2014. 
USDA: United States Departamento of Agriculture. Global Agricultural Information Network, Washington, fevereiro, 2013.

ZELIN, E.; BUSSOLARO, I.; SIMONETTI, A. P. M. M. Aplicação de silício no controle de lagartas e produtividade da cultura da soja. Cultivando o saber, Cascavel, v. 4, n. 1, p. 171-180, 2011. 